TS

260

H(6)?

MISTOR OF GOLD LEAF AND TMS USES

1915

xis

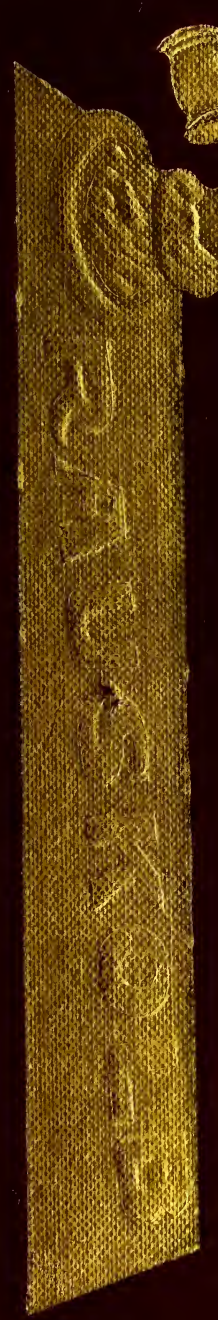

(1)X 








\section{HISTORY OF GOLD LEAF AND ITS USES}






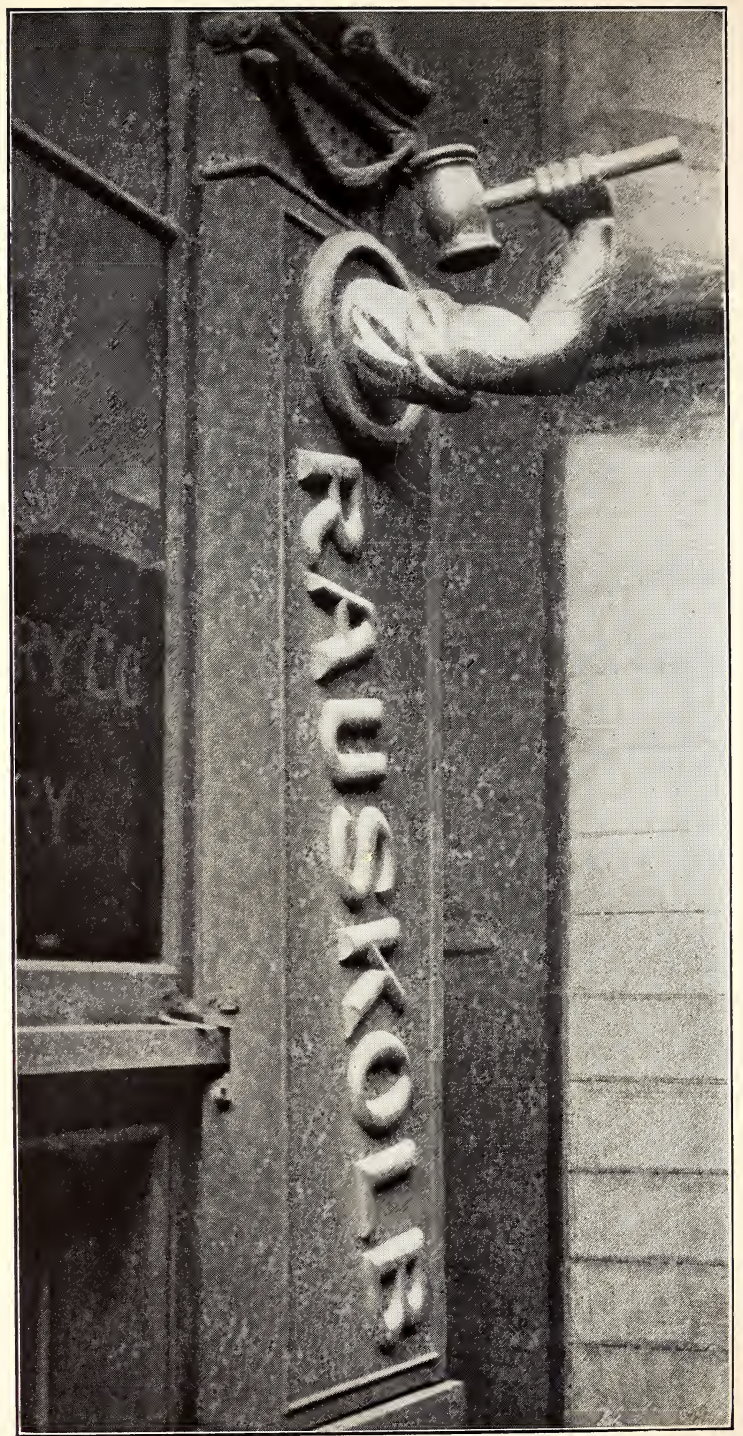




\section{History of Gold Leaf and Its Uses}

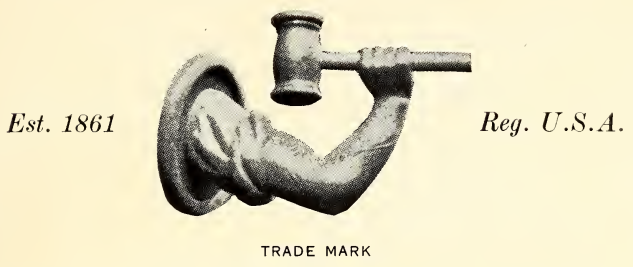

F. W. RAUSKOLB

103 ARCH STREET, - - BOSTON, MASS.

Manufacturer of

G OL D L E A F OF Every Description PATENT SIZED GOLD LEAF

Dealer in Silver, Aluminum, and Composition Leaf Bronze Powders, Liquid and Gold Size, White and Color Leaf, Gilders' Materials

SKE W I G G, RAGS, RUBBERS, A ND WASTE GOLD OF EVERY DESCRIPTION BOUGHT 
COPYRIGHT, I 9 I 5 , BY

F. W. RAUSKOLB 



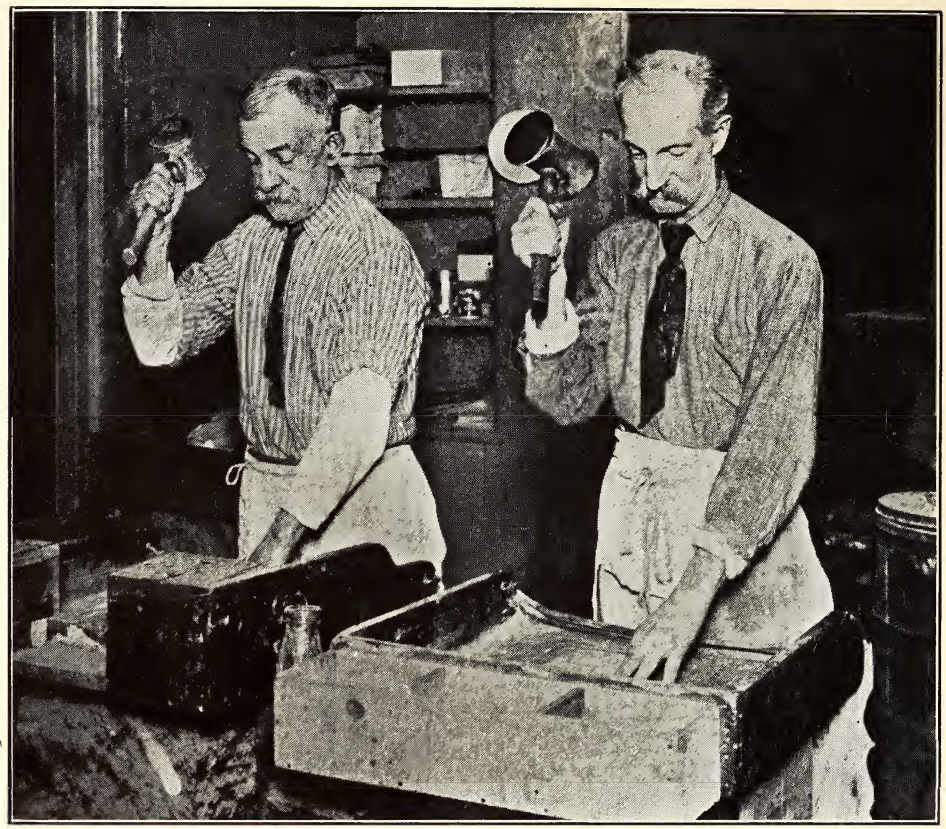

Two brothers who have worked continuously for us and our predecessors for over half a century. This is a record probably unparalleled in the world 


\section{The ש̌old Lbeaters}

YUGGESTIVELY a clever novel of fiction title, the above in this instance symbolizes a rare group of men in the "Athens of America," Boston, U.S.A., who wield heavy hammers daily pounding out the filmy sheets of Gold Leaf used so extensively in many branches of art and industry.

The art of Gold beating has existed for more than three thousand years, as is clearly shown by the quaint pictorial Egyptian stone tablets excavated in recent years by the scientific explorers. Gold was the most important substance used in decoration by the ancient craftsmen. 
"The Temple of Solomon was profusely gilt" says Homer in his writings. The Romans covered the ceilings and walls of their apartments with Gold Leaf. Nero erected his "Golden House" in Rome after the disastrous fire of 64 B.c. According to Tacitus "Italy and her provinces were pillaged and plundered to gratify the Emperor's love of magnificence." The jewelry and treasures of the people were probably dumped into the "melting pot" without much ceremony and the Gold beaten into thin sheets to cover the structure.

Down through the ages of man the precious yellow metal has been lavishly used for the adornment of himself and his domicile. It has been the standard, relatively speaking, of the position in life of its possessor. Even the mummy cases of the Egyptians give distinctive [6] 
evidence of their station in life. Some of these are covered with Gold Leaf and in some instances the bodies are encased in the precious metal.

The Egyptians used Gold Leaf for ornamentation more than twenty-five hundred years before the advent of the Christian Era and the Greeks are known to have made use of Gold Leaf fully 1400 B.c. The Chinese are also known to have covered their Idols with Gold Leaf many centuries ago. England, Germany and France have had "Gold beaters" for several hundred years. 


\section{ANCIENTS MINING GOLD}

7 HE production of Gold in the mines of Egypt is said to have

1 been over thirty-five million dollars annually in the time of Rameses II. which was 1400 B.c.

The toll in human life getting the Gold in those days is said to have been enormous. Men were then the slaves of the Princes and Rulers. Driven to the mines by the soldiery these unfortunates faced almost certain death. The mines are said to have been far from the governmental seats and to reach them the caravans crossed the great desert to the Upper Country.

Only the hardest kind of work was [8] 



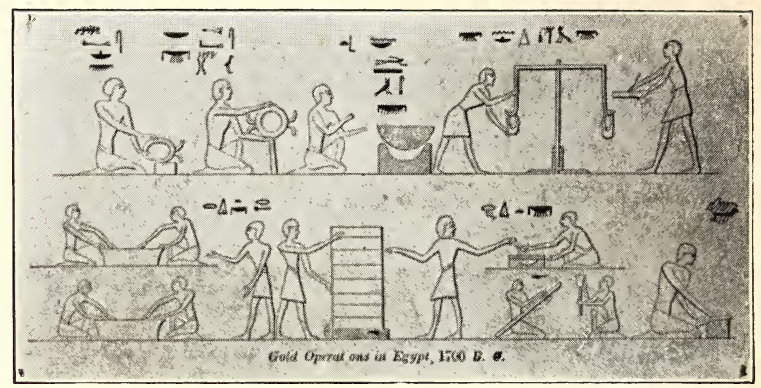


their lot, the water was scarce, having to be carried long distances and the food supply was very meagre. Under the cruel lash of the slave driver the men worked in the bowels of the earth mining the quartz rock which was brought to the surface by boys. It was then pounded with iron pestles, in stone mortars and then carried by the masters to the cities.

The methods of extracting and utilizing the Gold in those days are revealed by the Egyptian Hieroglyphics on the tomb of Beni-Hassan, of which the illustration opposite is a copy.

Reading of the drawing is from right to left, starting in the lower right-hand corner. The first man is working the quartz into a pulverized condition. The next man with the shovel places it on the inclined chute for the third man to 
screen. The fourth man is working with a pan in which water is poured by the fifth person. The latter also throws water into a "riffle" which is a series of steps. The others on the lower half are washing and stirring the material in the pans. The upper part shows the scribe with tablet and marker noting the weight on the scales. Then there is the man with the blow pipe at the crucible and the last two men are making the Gold into ornamental shapes.

\section{Extract from "Boston Globe" \\ JAN. 17, 1915}

The writer while walking through Arch St. recently heard heavy pounding. The sound came through a basement window and looking down men were seen hammering away with all their might on little packets that looked at first glance like a pack of cards. 
The next thing that attracted my attention was the big gilded figure of an arm and hammer sticking out over the entrance.

Men in an unusual business are usually courteous and willingly enlighten a stranger with information regarding their business. In this instance the owner, F. W. Rauskolb, was no exception.

After giving considerable data regarding the making of gold leaf, he permitted a tour of inspection of the shop under the guidance of the superintendent, but not before giving the "once over" in earnest. The reason for the latter action will be apparent when one considers that this is a gold beating shop, where there is gold in one form and another on all sides. Gold is gold whether in coins, bullion or gold leaf and it doesn't take much of it to make several dollars.

The first feature that impresses one on entering the shop, is the noise made by the men pounding with the hammers. They strike on sheepskin parchment, but the sound is heavy enough. The hammers weigh from 8 to 20 pounds each and with a score of them pounding it is very noisy. 
First was shown a nice little lump of the gold as it comes from the U. S. Treasury Department. A piece that resembled two yeast cakes laid end to end weighed $12 \frac{6}{10}$ ounces and was worth \$249.20. The weight and price were stamped on it.

The initial work done with the gold in the process is to melt it and add some silver alloy and copper. The amounts of the two last named metals vary according to the grade of leaf to be made. Some of it is necessary, anyway, for the pure gold could not be made into leaf without it, being too soft. Most of the gold leaf is of 23 carat, which is almost pure gold.

The metal is then poured into a mold, and after cooling is in a bar about five inches long and an inch wide, and about an eighth of an inch thick. This is rolled out into strips about 120 feet long, and as thin as a sheet of book paper. The boss then gives the gold beater a strip weighing 60 pennyweight, and he starts making the leaf.

For three days the beater has this bit of precious metal in his care. It is charged up to him, [12] 
and he is required to make 3000 sheets of leaf with it. It may take longer than three days to make the leaf, for the weather has a great deal to do with it, also the least indisposition of the beater shows marked effect.

His eye and hand must be steady, otherwise he may strike a few blows that will cause him to spend several hours to rectify the mistake.

The beater after getting the gold cuts it into little squares of about one inch, and he lays 200 of them between sheets of "cutch" paper.

This paper is made by a secret process in France. No substitute has been found for it that is suitable.

Finishing the cutting and arranging the little squares, he puts the pack into a parchment cover and starts the beating. Using the 20-pound hammer, he beats with one hand while with the other he keeps turning the "cutch." Each blow is struck with precision.

About half an hour is necessary for this part of the work, when the gold begins to show on the edges of the paper, having thinned out to four times the original size. 
These leaves are then taken and cut into four squares each with a "skewing" knife. The little squares are picked up with boxwood pincers and each is placed between ox intestinal skins.

These delicate skins are all imported from England, the process of curing them being known to but few people. The pack this time is known in the trade as the "shoder" and, placing the parchment cover on again, the beating is resumed.

After about two hours' work the 800 squares are flattened out until they appear on the edges of the skins, being then about four inches by four. These are cut into 3200 squares, by the use of a unique little instrument called a "wagon." It is like a little bobsled with runners made of lacquered cane from Japan.

They go through the beating process in ox skins. This pack is called the "mould" and is the final beating. The time taken in this last operation consumes on the average 12 hours and sometimes it takes much longer, depending on the weather, the eye and steadiness of the arm.

The leaves are so thin now that one can see [ 14 ] 
through them. It would take about 300,000 of them to make a pack one inch thick. Several years ago a quantity was measured at the Massachusetts Institute of Technology with the above result.

Rarely does a hole appear and when a small one does the girl who cuts and arranges them in little books of 25 each, patches it. Five dollars worth of gold would cover 5000 square inches of surface.

Although gold beating has been known to exist since 1706 в. с., it was first attempted in America about 100 years ago. The gold beaters soon found their way to Boston, and in the cellars of some of the old business houses of the Hub the sound of the hammer has been heard for almost a century.

The work is always carried on in a cellar, for if it was done on any other floor the building would soon be a wreck. It would be shaken down in a short time.

One of the most interesting features of gold beating is recovering the loose gold that escapes in the process. When for any reason a place 
is vacated the floors are taken up and burned and the gold recovered. Even the earth is burned. The ordinary sweepings of the shop yield $\$ 30$ for each barrelful.

This business has defied the mind and hand of the inventor all these years, for except in a few minor details the same methods have prevailed for the many centuries. Many attempts have been made to beat the gold with machinery with only partial success.

Besides the paper "cutch" from France, the ox skins from England and the cane from Japan, another paper is used that comes from Germany and England. This paper, which is originally used as business ledgers, is used to clean the ox skins of "brine" and impurities that accumulate during the process.

An imported powder is brushed on the skins after each operation with the foot of a Belgian hare. This prevents the leaf from sticking and breaking.

The sign of the arm and hammer over the door is an odd thing. It is over 50 years old and was made by one of the old-time wood [16 ] 
carvers who made the figure heads for the sailing vessels built in Quincy.

Supplementing this concise and interesting report of the Globe reporter the following facts are worthy of note.

There are eighteen colors of Gold Leaf made by us. The two most commonly used are "Deep" which is twenty-three carat and "Lemon" which is eighteen carat. Sometimes in order to lower the cost, the same color is held with a lower carat, but this is poor practice as the Leaf beaten from such metals is sure to tarnish.

The process of manufacture of Gold Leaf is carried on in much the same way as in the ancient days. The heavy hammer swung by the brawny arm still prevails, but improvements have been made in the initial rolling of the ingot 
and the receptacles for holding the leaves during the process of beating.

In the Egyptian period it is presumed that the Gold was beaten with copper or hard wooden hammers, until the metal was in thin sheets. The use of a skin from the entrails of cattle had its inception at a much later period in Eastern Europe. In the early part of the seventeenth century the Parisian Gold Leaf makers are said to have beaten an ounce of gold into 1600 leaves which would cover about 105 square feet, the equivalent of an extra large parlor rug. In 1711 the pellicle discovered by the Germans was used in France and a much greater area was attained. 


\section{IMPROVEMENTS}

7 HE first improvement of note in providing a more economical

and easily handled Gold Leaf was "Transfer Gold" made by sticking the Leaf to paper under pressure. It was patented about thirty years ago and is still used to advantage by sign painters and dome gilders working in the open where if the ordinary loose leaf was used it would blow away.

The second invention was "Roll Gold," the Leaf being laid on paper and rolled up, it was then cut to any desired width. These rolls have come into great demand and are used in practically all lines of work where Gold Leaf is used.

[19] 
The third and most important improvement in Gold Leaf manufacture is "Patent Sized Gold Leaf." It was invented especially for the shoe trade which today is one of the greatest industries of this U.S.A.

Before its discovery by us the leather or material was sized and thoroughly dried. The Gold Leaf was laid in position and held by a coating of olive oil. The impression was then made with a hot die and the surplus Gold collected by the use of a rubber sponge called "car-mu-cha."

With our "Patent Sized Gold Leaf" it is only necessary to place the leaf on the material, use a hot die and the imprint is complete. The waste stays on the paper thus saving every particle of Gold.

Another commendable feature of the [20 ] 
"Patent Sized Gold Leaf" is the absence of stains by its use. This alone makes it a most desirable product. In the few years it has been on the market several companies connected with the shoe trade have perfected machines for automatically feeding the material in ribbon form as the shoes are placed on the press.

The ease in which the "Patent Sized Gold Leaf" can be handled on any machine is a great advantage over any other embossing material now on the market. A permanent trade-mark or other advertisement is secured which cannot be produced with any other material except real Gold Leaf. It will not change or tarnish. It is put up in sheets, strips and rolls. 



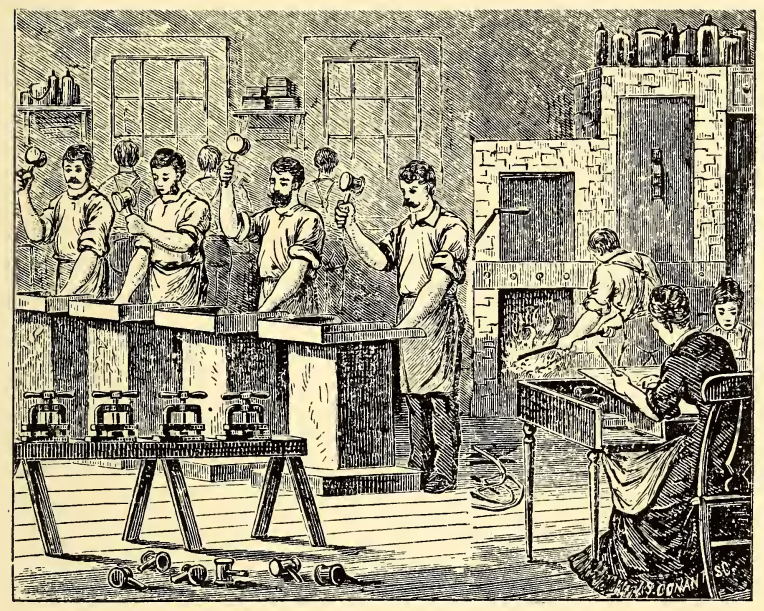






